\title{
CHARACTERIZATION OF A CONSERVED REGION AT MITOCHONDRIAL CYTOCHROME B GENE IN CAMEL, DONKEY AND RAT FOR MEAT SPECIES IDENTIFICATION.
}

\author{
Z.G. Abdel-Hameid ${ }^{1}$, M.S. Hassanane ${ }^{1 *}$, H.M. El-Ashmaoui ${ }^{1,3}$ I.A.H, \\ Barakat $^{1}$, S. Abd El-Baset ${ }^{2}$ and B. Elsalkh ${ }^{2}$ \\ 1- Cell Biology Department, National Research Center, Dokki, Giza, Egypt, 2 - \\ Department of Zoology, Faculty of Science (Girls Branch), Al-Azhar University, 3- \\ Department of Biological Science, Faculty of Science, King Abdel-Aziz University, \\ Geddah
}

\section{SUMMARY}

Two ways or double strand sequencing was employed for sequencing a conserved part from the mitochondrial cytochrome $b$ gene in three mammalian species (camel, donkey and rat). The aim of the sequencing was to identify the species specific point mutation and establishing a restriction map for unique cutting with restriction enzymes for the three species under study. For performing the study, the DNA were obtained from animal tissues using CTAB methodology, the Polymerase Chain Reaction was performed using universal primer set for amplification a conserved part of the mitochondrial cytochrome $\mathrm{b}$ gene. The resulted fragments (359bp) were sequenced using BigDye terminator on automated ABI DNA genetic analyzer. All the obtained sequences were submitted to the GenBank sequence and alignment using the program BLASTn. Sequence comparison with a BLASTn search software, the search resulted in correspondences with homologies percentage from the sequence of the tested species to the sequence in the GenBank database, the score similarity in camel samples are record that $99 \%-100 \%$ with one humped camel (Camelus dromedarius); in donkey samples are record 98\% -100\% similarity with the domestic donkey (Equus asinus) and in rat samples are record 98\%-100\% similarity with rat (Rattus norvegicus). The Webcutter 2.0 software was used for identifying the restriction enzyme cutting sites. The results recorded specific recognition for each species. The specificity of the point mutation of the conserved cytochrome $b$ gene adopted in this study proved to be valuable in animal meat species identification and can be further used for processed meat identification for halal authentication and controlling fraud or misdescription.

Keywords: PCR, Meat species identification, DNA sequencing, mitochondrial cytochrome b gene 